\title{
Physico-chemical and rheological properties of gelatinized/freeze-dried cereal starches
}

\author{
Magdalena Krystyjan ${ }^{1 *}$, Wojciech Ciesielski ${ }^{2}$, Dorota Gumul ${ }^{1}$, Krzysztof Buksa ${ }^{1}$, Rafat Ziobro ${ }^{1}$, \\ and Marek Sikora ${ }^{1}$ \\ ${ }^{1}$ Department of Carbohydrate Technology, Food Technology Faculty, University of Agriculture, Balicka 122, \\ 30-149 Kraków, Poland \\ ${ }^{2}$ Institute of Chemistry, Environmental Protection and Biotechnology, Jan Długosz University, \\ Armii Krajowej 13/15, 42-201 Częstochowa, Poland
}

Received November 22, 2016; accepted May 31, 2017

\begin{abstract}
The influence of gelatinization and freeze-drying process on the physico-chemical and rheological properties of cereal starches was evaluated, and it was observed that modified starches revealed an increased water binding capacity and solubility when compared to dry starches, while exhibiting the same amylose and fat contents. The molecular weights of starches decreased after modification which resulted in the lower viscosity of dissolved modified samples in comparison to native starch pastes. As it was observed by scanning electron microscopy modified starches were characterized by an expanded surface, a uniform structure and high porosity.

Keywords: cereal starch, gelatinization, freeze-drying process
\end{abstract}

\section{INTRODUCTION}

More than a century of research on starch has led to the elaboration of various methods of starch modification allowing the adjustment of the properties of this polysaccharide for the needs of the food and non-food industries. The starch has been modified by means of physical, chemical and biochemical treatments in numerous ways (Tomasik and Zaranyika, 1995; Tomasik and Schilling, 2004; Gumul et al., 2014). Preferable methods should not change the chemical composition of starch glucans, since it is assumed that they are metabolized into the body in the same way as native starch (Tomasik and Schilling, 2004; Tomasik and Zaranyika, 1995).

The freeze-drying process is a well-established technique of preservation, and its main objective is to eliminate water from the pre-frozen product, thus omitting the formation of a liquid phase (Ratti, 2012; Spieles et al., 1995).

*Corresponding author e-mail: m.krystyjan@ur.krakow.pl

**This work was financed by the Ministry of Science and Higher Education of the Republic of Poland, Grant No. BM-4723, 2012.
This method significantly extends the shelf life of food products, since the removal of water inhibits any reactions that would be deemed undesirable. The freeze-drying process has found a variety of applications, mainly in the pharmaceutical industry, and also within biotechnology and medicine (Nussinovitch et al., 1998).

While the freeze-drying of starch gels results in a range of products with extended shelf lives, it significantly affects their physical form and, to some extent their chemical properties. The dissolving of native starch requires gelatinization, and this leads to a partial or the complete degradation of its structure. The hydrogen bonds that stabilize the structure of the macromolecules are interrupted, and as a consequence the starch loses its crystallinity. Freezedried starch gels, known as starch sponge, have a strongly developed surface and a uniform structure which facilitates chemical reactions (Jouppila and Roos, 1997; Juszczak et al., 2004; Lee and Rhee, 2007; Leszczyński, 1992). They strongly absorb water and show significant susceptibility to enzyme activity (Tomasik and Zaranyika, 1995). Starch sponge, free from any toxic reagents, can be used in the food industry, as a biodegradable material (Hofmann et al., 1998) and in the pharmaceutical industry as an excipient in sustained release tablets (Sánchez et al., 1995).

The properties of the freeze-dried starch gels are strongly influenced by the drying parameters, in particular temperature and pressure (Spieles et al., 1995). Lee and Rhee (2007) investigated the effects of the temperature, the time of the freeze-drying process, and the concentration of starch on the rice starch gels properties. They proved that controlling the process parameters enabled obtaining

(C) 2017 Institute of Agrophysics, Polish Academy of Sciences 
the required properties of a solid rice starch matrix. In turn, Shi et al. (2012a) compared the rheological properties of the suspension that contained cross-linked starch nanoparticles prepared by spray and vacuum freeze-drying methods. Starches obtained by such methods exhibited different viscoelastic and thixotropic properties. In another work, the same authors studied the impact of annealing and cryoprotectants on the properties of lyophilized starch nanoparticles (Shi et al., 2012b). Juszczak et al. (2004) focusing on freeze-dried wheat starch gels only investigated their rheological properties. Currently however, there are no studies on the comprehensive physico-chemical properties of freeze-dried cereal starch gels, and little is known about the extent of the changes in the rheological behaviour of starch pastes as a result of freeze-drying and subsequent re-dissolving. Among the physico-chemical properties that may be most important for any industrial application is the amylose and amylopectin content. Their water binding capacity and solubility in water, rheological properties and molecular weight should also be mentioned.

Therefore, the aim of this study was to analyze and compare the physico-chemical properties of freeze-dried starch gels that have been obtained from cereal starches (wheat, rye and oat).

\section{MATERIALS AND METHODS}

Native oat starch (OSN) was isolated from oats (Polan variety) according to the method proposed by Paton (1977), using aqueous sodium carbonate (pH 10) at $45^{\circ} \mathrm{C}$ for extraction. Native rye starch (RSN) was isolated from rye (Dańkowskie Złote variety), and native wheat starch (WSN) was isolated from wheat (Almari variety) according to Richter et al. (1969). Starch from rye or wheat flour was separated by preparing dough with a $1 \% \mathrm{NaCl}$ solution and washing out the starch granules with $0.1 \% \mathrm{NaCl}$ solution. Further cleaning from grain protein was done by means of density separation using sedimentation and centrifugation. The obtained starch granules were dried at room temperature and sieved through a $0.12 \mathrm{~mm}$ sieve.

In order to obtain modified starches (OSL, RSL, WSL), native starches were dissolved in deionized water to obtain a final concentration of $5 \%$ ( $\%$, mass d.m.). The dispersions were mixed for 20 min with intensive stirring (400 r.p.m.), and heated at $96^{\circ} \mathrm{C}$ for a further 20 min stirring at the same speed. The starch pastes that were obtained as a result were placed into plastic containers in amounts of $40 \mathrm{ml}$ and cooled in a ice bath at $5^{\circ} \mathrm{C}$ over a period of $10 \mathrm{~min}$. Then the samples were frozen at $-25^{\circ} \mathrm{C}$ for $24 \mathrm{~h}$ and freeze-dried (Labconco, USA). The sample was then ground in the Grindomix GM 200 mill laboratory (Retsch, Haan, Germany) for seven seconds at 6000 r.p.m.

The ultra-high scanning electron microscope (SEM), with a field emission cannon (FEG - emitter SCHOTKYEGO) - NOVA NANO SEM 200 (manufacturer FEJ EUROPE
COMPANY) with adapter for micro-chemical analysis (EDS) was used. The resolving power of up to $2 \mathrm{~nm}$ and a magnification of $70-500000 \mathrm{x}$, was applied.

Texture parameters of $5 \%$ ( $\%$, mass d.m.) freeze-dried starch gels were determined by means of a TA-XT plus texture analyzer (Stable Micro Systems, Haslemere, UK). The samples were penetrated in the centre to a $75 \%$ strain, using a $\mathrm{P} / 20$ aluminium cylinder, moving at $5 \mathrm{~mm} \mathrm{~s}^{-1}$. After a pause $(5 \mathrm{~s})$ a second cycle of penetration was performed, and the values obtained were used to calculate texture parameters following the TPA method. The reported data are the averages of ten replications.

To determine the apparent amylose content (blue complex with iodine), the measurement (run in triplicate) was performed spectrophotometrically according to Morrison and Laignelet (1983). $120 \mathrm{mg}$ of starch was dissolved in $20 \mathrm{ml}$ of UDMSO solution $(100 \mathrm{ml}$ of $6 \mathrm{M}$ urea combined with $900 \mathrm{ml}$ dimethylsulfoxide) in an Erlenmayer flask, shaken for $3 \mathrm{~h}$ and stored overnight. After $24 \mathrm{~h}$ the flask was shaken for $1 \mathrm{~h}$ in a water bath heated to $90^{\circ} \mathrm{C}$. $1 \mathrm{ml}$ of the solution was transferred to a $100 \mathrm{ml}$ volumetric flask, mixed with $90 \mathrm{ml}$ of distilled water and $2 \mathrm{ml}$ iodine solution ( $0.2 \%$ of iodine in $2 \% \mathrm{KI}$ solution, mass) and filled with water. The absorbance of the solution was measured after $15 \mathrm{~min}$, at $635 \mathrm{~nm}$. A blank sample contained $1 \mathrm{ml}$ UDMSO, $97 \mathrm{ml}$ water and $2 \mathrm{ml}$ iodine solution. The blue value $(B V)$ was expressed using the formula:

$$
B V=\frac{A 10}{m},
$$

where: $A-$ is the absorbance, $m$ - is the mass of starch (mg).

Water binding capacity (WBC) and solubility (S) at 25,40 and $70^{\circ} \mathrm{C}$ were determined using Leach (1965) modified gravimetric procedure. Starch samples $(1.0 \mathrm{~g}$ dry residue in each) were suspended in $70 \mathrm{ml}$ of distilled water and heated at 25,40 and $70^{\circ} \mathrm{C}$ for 30 min on agitation (200 r.p.m.). The samples were then centrifuged for $10 \mathrm{~min}$ at 2500 r.p.m. Supernatant was dried and used for calculation of solubility and solid remnants were the basis for a gravimetric determination of WBC. Determinations were run in triplicate.

The molar mass of starch was evaluated by the HPSEC method, after dissolving the samples in DMSO (Buksa et al., 2013). The HPSEC system consisted of a Smartline 1000 HPLC pump (Knauer, Germany), a valve with a $100 \mu \mathrm{L}$ injection loop, a set of columns connected in series: OHpak SB-G (guard), OHpak SB-806 and OHpak SB 804 (Shodex, Japan) which were connected in series and refractive index (RI) detector (Knauer, Germany). An aqueous solution of $100 \mathrm{mM} \mathrm{NaNO}_{3}$ was used as eluent at a flow rate of $0.6 \mathrm{~mL} \mathrm{~min}^{-1}$; the separation was conducted at a column temperature of $60^{\circ} \mathrm{C}$. The system was calibrated with pullulan standards (Shodex Standard, Machereye Nagel) with known molar masses (P-5, 10, 100, 400 and 800) and 
glucose (Sigma Aldrich). Molar mass distribution was used to calculate the weight average molar mass $\left(\mathrm{M}_{\mathrm{w}}\right)$, number average molar mass $\left(\mathrm{M}_{\mathrm{n}}\right)$, and dispersity $\left(\mathrm{D}=\mathrm{M}_{\mathrm{w}} / \mathrm{M}_{\mathrm{n}}\right)$ using Eurochrom (ver. 3.05, Knauer) and Clarity (ver. 4.0.1.700, DataApex) software.

Aqueous suspensions of $5 \%(\mathrm{w} / \mathrm{w}$, calculated for dry residue) native and modified starches were prepared for rheological analysis. Suspensions were heated at $96^{\circ} \mathrm{C}$ for 20 min with intensive stirring at 400 r.p.m. Flow curves were registered with a RheoStress RS 1 (Gebrueder Haake $\mathrm{GmbH}$, Karlsruhe, Germany) rheometer in the CR mode with Z34 Ti measuring system. Measurements were conducted at $50^{\circ} \mathrm{C}$. The shear rate was raised from 1 to $300 \mathrm{~s}^{-1}$, over a 10 min period, followed by a constant shear rate of $300 \mathrm{~s}^{-1}$, for $1 \mathrm{~min}$, and a subsequent decrease of shear rate from 300 to $1 \mathrm{~s}^{-1}$, over a $10 \mathrm{~min}$. Obtained flow curves were described by Ostwald de-Waele rheological models:

$$
\tau=K(\dot{\gamma})^{n},
$$

where: $\tau$ - shear stress $(\mathrm{Pa}), K$ - consistency coefficient $\left(\mathrm{Pa} \mathrm{s}^{\mathrm{n}}\right), \dot{\gamma}$ - shear rate $\left(\mathrm{s}^{-1}\right)$, and $n$ - flow behaviour index.

The areas of thixo- and antithixotropy hysteresis loops were calculated according to Sikora et al. (2015) by the summing-up of the areas of particular trapeziums formed between the curve 'up' and 'down'.

The experimental data were subjected to analysis of variance (Fisher test), at a confidence level of $p<0.05$, by use of the Statistica v. 8.0 (Statsoft, Inc., Tulsa, OK., USA) software program.

\section{RESULTS AND DISCUSSION}

The SEM micrographs obtained (Fig. 1) revealed a significant destruction of the granular structure of starches after their gelatinization and freeze-drying process, and their subsequent transformation into a sponge occurred. It was noted that such starches had strongly developed surface and a uniform structure, which should facilitate contact with other reagents. Due to their high porosity starch sponges can be successfully used as an internal or external absorbents (Nussinovitch et al., 1998) or as a pharmaceutical excipient and hydrophilic matrices (Sánchez et al., 1995).

The texture parameters of freeze-dried starch gels were characterized by large coefficients of variance (the average CV for WSL, RSL and OSL were 42, 25, and 31\%, respectively), which demonstrates a high variability between individual freeze dried samples (Table 1). However, some statistically important differences between dried gels could also be observed, especially between oat starch and two other samples. Freeze-dried 5\% oat starch paste revealed the lowest hardness, springiness and chewiness, while exhibiting a maximum cohesiveness and resilience in comparison to other freeze-dried starch gels. The differences were especially visible in hardness (which in the case of OSL equalled only $45 \%$ of the hardest - WSL sample) and

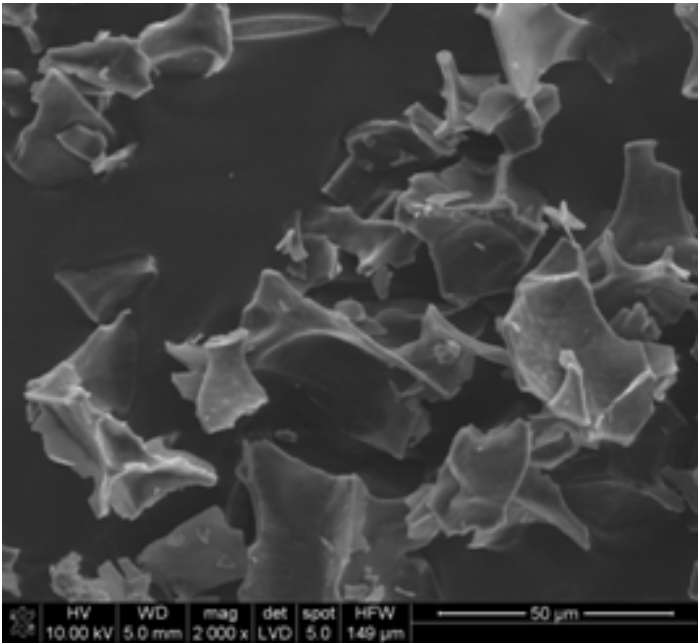

b

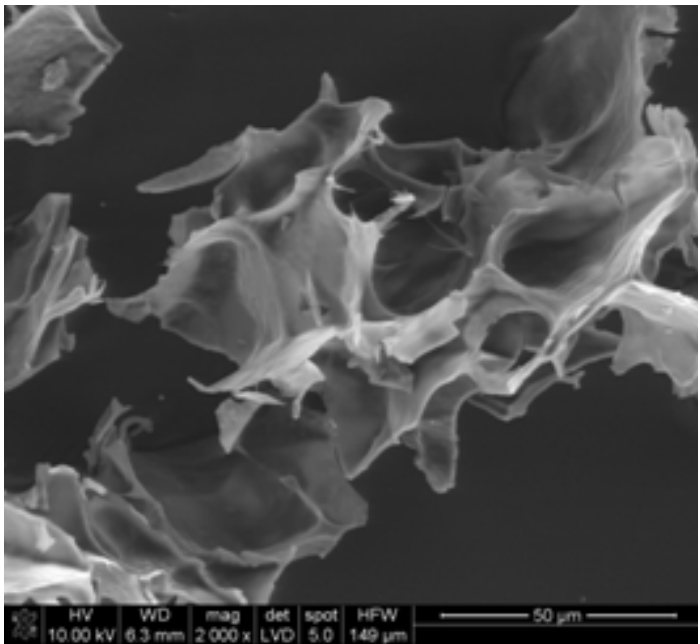

c

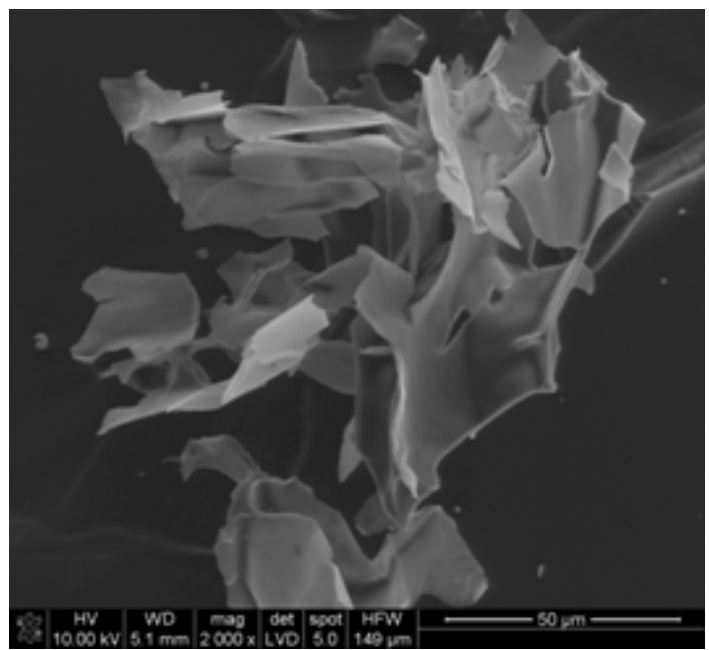

Fig. 1. SEM micrographs of modified starches of $a-$ wheat, $b-$ rye, and $\mathrm{c}-$ oat. 
T a b l e 1. Texture parameters of freeze-dried $5 \%$ starch gels

\begin{tabular}{lllllll}
\hline Sample & \multicolumn{1}{c}{$\begin{array}{c}\text { Hardness } \\
(\mathrm{N})\end{array}$} & \multicolumn{1}{c}{ Springiness } & Cohesiveness & $\begin{array}{c}\text { Gumminess } \\
(\mathrm{N})\end{array}$ & \multicolumn{2}{c}{$\begin{array}{c}\text { Chewiness } \\
(\mathrm{N})\end{array}$} \\
\hline WSL & $40.51 \pm 12.20 \mathrm{c}$ & $0.62 \pm 0.22 \mathrm{ab}$ & $0.14 \pm 0.05 \mathrm{a}$ & $5.36 \pm 2.27 \mathrm{~b}$ & $3.45 \pm 2.23 \mathrm{~b}$ & $0.04 \pm 0.02 \mathrm{~b}$ \\
RSL & $28.60 \pm 5.14 \mathrm{~b}$ & $0.73 \pm 0.18 \mathrm{~b}$ & $0.114 \pm 0.02 \mathrm{a}$ & $3.19 \pm 0.70 \mathrm{a}$ & $2.40 \pm 0.88 \mathrm{ab}$ & $0.04 \pm 0.01 \mathrm{~b}$ \\
OSL & $18.24 \pm 4.01 \mathrm{a}$ & $0.46 \pm 0.09 \mathrm{a}$ & $0.20 \pm 0.06 \mathrm{~b}$ & $3.58 \pm 1.41 \mathrm{a}$ & $1.64 \pm 0.76 \mathrm{a}$ & $0.09 \pm 0.02 \mathrm{a}$ \\
\hline
\end{tabular}

Parameters in columns denoted with the same letters do not differ statistically at the level of confidence $\mathrm{p}<0.05$.

T a b l e 2. Apparent amylose content, solubility and $\mathrm{WBC}$ (at 25,40 , and $70^{\circ} \mathrm{C}$ ) of native and modified starches

\begin{tabular}{|c|c|c|c|c|c|c|c|c|}
\hline \multirow{3}{*}{ Sample } & \multirow{2}{*}{$\begin{array}{l}\text { Aparent } \\
\text { amylose } \\
\text { content }\end{array}$} & \multirow{2}{*}{ Lipids } & \multicolumn{3}{|c|}{ WBC ( $\mathrm{g} \mathrm{g}^{-1}$ d.m.) } & \multicolumn{3}{|c|}{$\mathrm{S}(\%, \mathrm{mass})$} \\
\hline & & & 25 & 40 & 70 & 25 & 40 & 70 \\
\hline & \multicolumn{2}{|c|}{$(\%$, mass $)$} & \multicolumn{6}{|c|}{$\left({ }^{\circ} \mathrm{C}\right)$} \\
\hline WSN & $20.02 \pm 0.11 \mathrm{e}$ & $0.49 \pm 0.02 \mathrm{a}$ & $0.78 \pm 0.00 \mathrm{a}$ & $0.84 \pm 0.01 \mathrm{a}$ & $6.05 \pm 0.00 \mathrm{~b}$ & - & $0.24 \pm 0.05 a$ & $2.56 \pm 0.06 \mathrm{a}$ \\
\hline WSL & $17.06 \pm 0.02 \mathrm{~d}$ & $0.45 \pm 0.02 \mathrm{a}$ & $8.58 \pm 0.01 \mathrm{c}$ & $7.91 \pm 0.01 \mathrm{c}$ & $8.51 \pm 0.01 \mathrm{c}$ & $0.3 \pm 0.08 \mathrm{a}$ & $1.50 \pm 0.14 \mathrm{c}$ & $4.16 \pm 0.00 \mathrm{c}$ \\
\hline RSN & $22.96 \pm 0.12 f$ & $0.45 \pm 0.04 \mathrm{a}$ & $0.81 \pm 0.00 \mathrm{a}$ & $0.87 \pm 0.00 \mathrm{a}$ & $6.30 \pm 0.03 b$ & - & $0.69 \pm 0.00 \mathrm{~b}$ & $5.16 \pm 0.36 \mathrm{~d}$ \\
\hline RSL & $19.77 \pm 0.11 \mathrm{e}$ & $0.43 \pm 0.02 \mathrm{a}$ & $9.82 \pm 0.03 \mathrm{~d}$ & $9.00 \pm 0.07 \mathrm{~d}$ & $8.91 \pm 0.06 \mathrm{c}$ & $1.32 \pm 0.28 b$ & $3.30 \pm 0.08 \mathrm{~d}$ & $5.68 \pm 0.45 \mathrm{~d}$ \\
\hline OSN & $15.50 \pm 0.04 \mathrm{c}$ & $1.10 \pm 0.07 \mathrm{~b}$ & $1.05 \pm 0.01 \mathrm{~b}$ & $1.06 \pm 0.00 \mathrm{~b}$ & $5.35 \pm 0.02 \mathrm{a}$ & - & $0.75 \pm 0.12 b$ & $3.57 \pm 0.39 b$ \\
\hline OSL & $9.75 \pm 0.13 \mathrm{a}$ & $1.12 \pm 0.10 \mathrm{~b}$ & $10.21 \pm 0.6 \mathrm{e}$ & $11.56 \pm 0.63 \mathrm{e}$ & $11.96 \pm 0.04 d$ & $4.79 \pm 0.52 \mathrm{e}$ & $5.48 \pm 0.06 \mathrm{e}$ & $6.01 \pm 0.38 \mathrm{e}$ \\
\hline
\end{tabular}

Explanations as in Table 1.

resilience (which was more than two times higher than the two remaining samples). These data could be explained by the differences in the pasting behaviour between oat starch and other cereal starches which are caused by starch granule size (oat starch has the smallest granules) (Zhou et al., 1998), and the level of lipids (the highest being in oat starch) (Table 2). It seems that freeze-dried oat starch gels are more delicate (little hardness) than other samples, but under deformation are rather compressed (small springiness) than cracked (relatively high cohesiveness and resilience). Differences between freeze-dried wheat and rye starch gels were most pronounced in the case of hardness and gumminess. It has been shown (Lee and Rhee, 2007) that texture parameters of rice starch matrices could be affected both by starch concentration and heating procedure, which is responsible for a degree of gelatinization and gel microstructure.

Among the tested starches the highest apparent amylose content was indicated in native rye starch (approximately $23 \%$ ) and the lowest (15.5\%) in native oat starch (Table 2). These values were similar to the ones provided in literature (Autio and Eliasson, 2009; Gomand et al., 2011; Swinkels, 1985). It was found that the apparent amylose content of the modified starches was significantly lower in relation to their native counterparts. In the case of WSL and RSL it was observed to be approximately $14 \%$ less apparent amylose content in comparison to the native starches. However, in the OSL, apparent amylose con- tent was almost $37 \%$ lower compared to the native. The reduction of the apparent amylose content in the modified starches could be explained by the retrogradation of amylose during the cooling and freezing of starch gels prior to the freeze-drying process rather than its depolymerization. This hypothesis was confirmed by molecular mass analysis (Fig. 2). When comparing the shape of the molecular mass distribution profiles of native and modified starches, there was no significant increase of low molecular mass fraction $\left(\mathrm{M}_{\mathrm{w}}<500000 \mathrm{~g} \mathrm{~mol}^{-1}\right)$ observed, which could testify for the partial depolymerization of amylose chains. It could be supposed that amylose retrogradation, which occurred as a result of modification by gelatinization/freeze-drying, could hinder the amylose-iodine complex formation by changing the amylose conformation. Consequently, lower apparent amylose content in modified starches was determined by the colorimetric method. Similar problems with the results of the above method were often described in literature (Gumul et al., 2014; Pietrzyk and Fortuna, 2005; Praznik et al., 2012). Among the native starches, the highest fat content was revealed to be oat starch $(1.1 \%)$, which is consistent with the literature, according to which these values range from 1 to 3\% (Gudmundsson and Eliasson, 1989). WSN and RSN were characterized by more than 2-fold lower levels of lipids than OSN (Table 2). The gelatinization/freeze-drying process did not affect the fat content in the cereal starches. Presumably, the quantity of fat has not changed during the sample modification, but the 


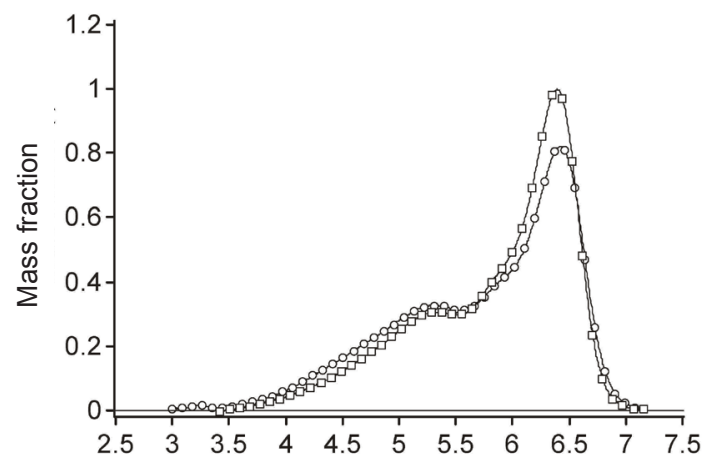

b
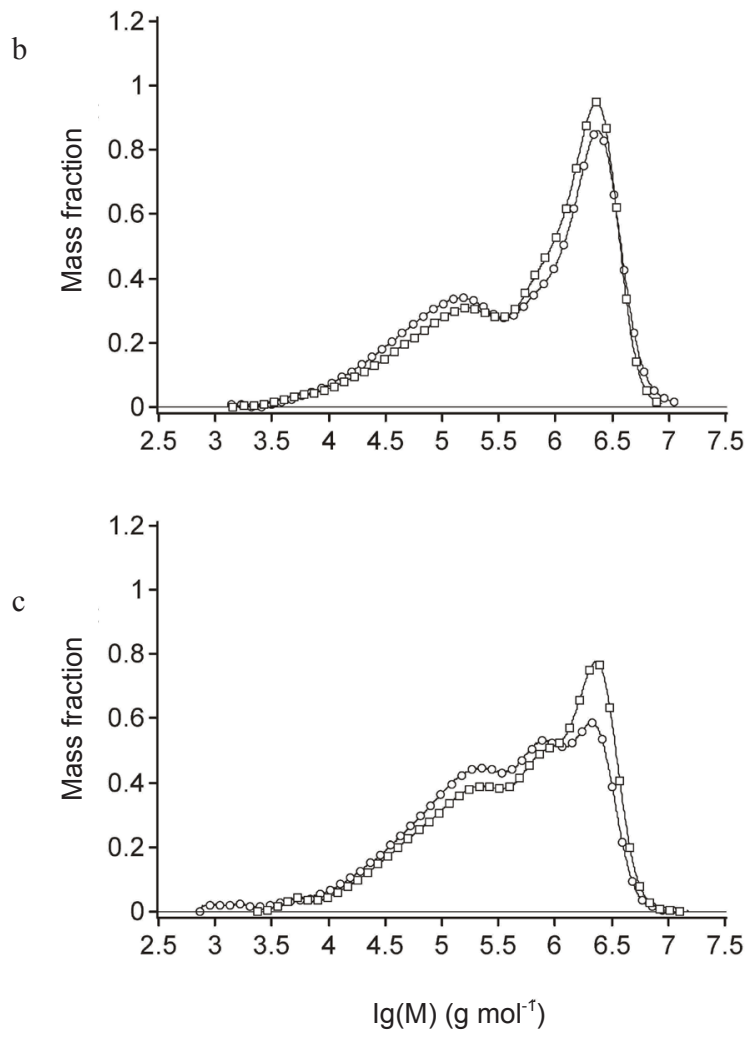

Fig. 2. Molecular mass $\left(\mathrm{M}_{\mathrm{w}}\right)$ distribution profiles of starches dissolved in DMSO: native (-๑-) and modified (-०-), obtained from: $\mathrm{a}$ - wheat, b-rye, c - oat.

retrogradation of amylose contributed to the breakdown of amylose-lipid complexes. This assumption was confirmed by rheological data (Fig. 3). Whole modified starch gels exhibited lower viscosity and were more fragile to shear force than native starches.

Water binding capacity (WBC) and solubility (S) are highly important starch features. Therefore, in our present study, these properties were determined at three temperatures: 25,40 and $70^{\circ} \mathrm{C}$. It was found that the WBC of modified starches determined at 25 and $40^{\circ} \mathrm{C}$ was 9 -fold greater than of natural starch. This rapid increase in WBC by all modified starches was almost identical in these two temperatures. $\mathrm{WBC}$ that was carried out at $70^{\circ} \mathrm{C}$ of wheat and rye modified starch showed a $41 \%$ increase in comparison to native starch. The largest increase in this parameter was observed in the OSL, which was about a $123 \%$ increase relative to the native starch (OSN). The modified oat starch showed higher water binding capacity in the analyzed temperature range of $25-70^{\circ} \mathrm{C}$ than RSL and WSL.

The solubility of modified starches was also higher in comparison with native starches where at $40^{\circ} \mathrm{C}$ 4-7-fold, and at $70^{\circ} \mathrm{C} 1.1-1.6$-fold, an increase was seen in the solubility of the gelatinized/freeze-dried starches when compared to the native samples. This parameter increased with the raised temperature, and a higher solubility of modified starches was noticed in the oat starch. However, an increase in WBC and S of the modified starches is highly advantageous, and this is reflected in the changes in the structure of these starches. These was confirmed by SEM analysis (Fig. 1).

The molecular properties of starches both native and modified were determined by a calibrated HPSEC/RI system. The shape of the molecular mass distribution profiles (Fig. 2) of native rye and wheat starches was typical, along with a distinctive two peaks: the lower was in the range of $\mathrm{M}_{\mathrm{w}}<500000 \mathrm{~g} \mathrm{~mol}^{-1}$, corresponding mainly to amylose fraction and the higher one, in the range of $\mathrm{M}_{\mathrm{w}}>$ $500000 \mathrm{~g} \mathrm{~mol}^{-1}$, which was originating from amylopectin. In the case of native oat starch, the third distinctive peak was observed in the range of $\mathrm{M}_{\mathrm{w}} 500000-1000000 \mathrm{~g} \mathrm{~mol}^{-1}$, and its occurrence could be interpreted as the presence of intermediate starch fraction between amylose and amylopectin. The presence of this fraction could be explained by partial hydrolysis of amylopectin fraction or an improved solubility of starch aggregates after alkali treatment during starch isolation (Paton, 1977; Praznik et al., 2012).

On the basis of molecular mass distributions, the molecular parameters $\left(\mathrm{M}_{\mathrm{w}}, \mathrm{M}_{\mathrm{n}}\right.$, and dispersity) of examined starches were calculated (Table 3). The highest molar mass $\left(\mathrm{M}_{\mathrm{w}}\right)$ was determined for WSN, and the lowest for OSN. Comparing the values of molar masses $\left(\mathrm{M}_{\mathrm{w}}\right)$ for gelatinized/freeze-dried and native starches, it was only in the case of oat starch that the molar mass was determined after the modification was significantly lower, compared to prior modification.

However, comparing the shapes of molecular mass distribution profiles before and after modification, it could be seen that for all examined starches, the area under the amylopectin peak (in the range of $\mathrm{M}_{\mathrm{w}} 1000000-10000000 \mathrm{~g}$ $\mathrm{mol}^{-1}$ ) was slightly lower, and the area in the lower range of $M_{w}\left(M_{w}<1000000 \mathrm{~g} \mathrm{~mol}^{-1}\right)$ was slightly higher, which may reveal that modification could improve the solubility of high molar mass starch aggregates. The problem of the proper dissolving of starch molecules is described extensively in literature and until now there is no optimal method for starch dissolving (Gilbert et al., 2010; Gidley et al., 2010; Praznik et al., 2012). The better dissolving of starch 


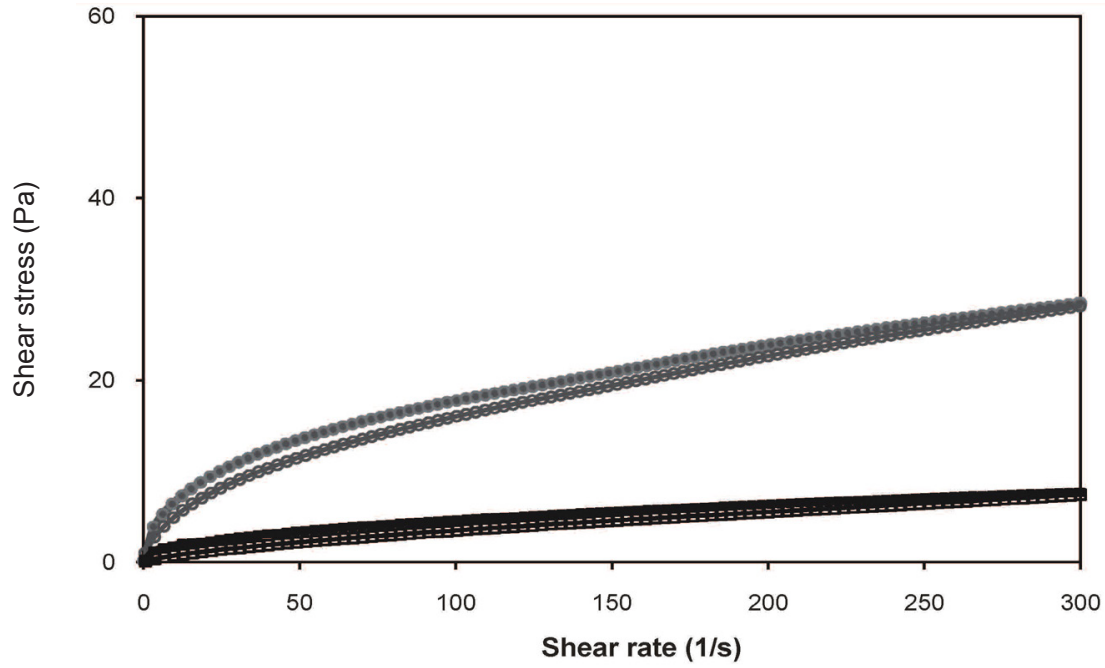

$\because W S N$-up $\longrightarrow$ WSN_down $\longrightarrow$ WSL_up $\longrightarrow$ WSL_down

b

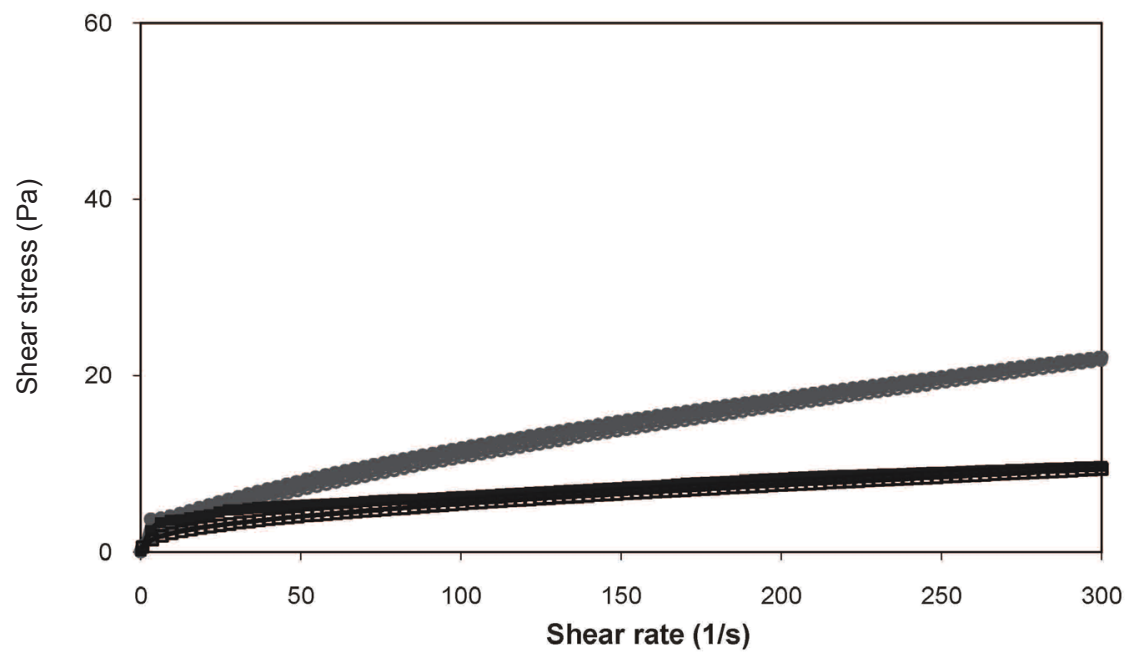

c

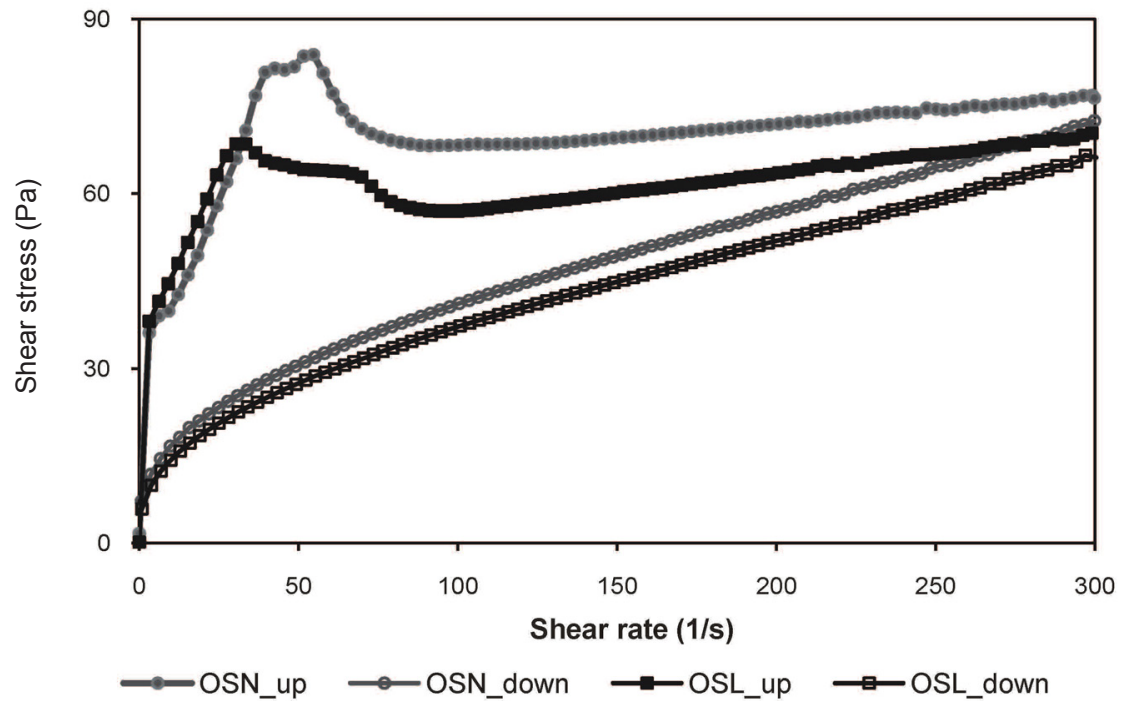

Fig. 3. Flow curves of native and modified starches of: a) wheat, b) rye and c) oat. 
T a b l e 3. Molecular parameters of native and modified starches

\begin{tabular}{cccc}
\hline \multirow{2}{*}{ Sample } & \multicolumn{2}{c}{$\mathrm{M}_{\mathrm{n}}$} & \multirow{2}{*}{$\mathrm{M}_{\mathrm{w}}$} \\
\cline { 2 - 3 } & \multicolumn{2}{c}{$\left(\mathrm{g} \mathrm{mol}^{-1}\right)$} & 10.1 \\
\hline WSN & 150290 & 1513100 & 17.9 \\
WSL & 82600 & 1477260 & 14.6 \\
RSN & 89470 & 1304180 & 14.4 \\
RSL & 93180 & 1343270 & 10.8 \\
OSN & 106420 & 1148820 & 17.9 \\
OSL & 50450 & 901970 & \\
\hline
\end{tabular}

aggregates in the case of gelatinized/freeze-dried samples compared to native ones, by the more efficient breakage of hydrogen bonds between polysaccharide chains in aggregates, was also confirmed by solubility measurements (Table 2), as well as viscosity measurements presented in this work (Table 4).

The behaviour of aqueous suspensions of native and modified starches after heating to $96^{\circ} \mathrm{C}$ for 20 min was characteristic for non-Newtonian, pseudoplastic liquids (Fig. 3). This is typical for such mixtures (Sikora et al., 2010), and the observed thinning (decrease of viscosity) occurs due to applied shear forces. Among the examined native cereal starch gels, the OSN exhibited the highest viscosity (Table 4). The swelling of granules proceeded more slowly than in other starches due to the presence of amylose-lipids complexes which according to Craig et al. (1989) behave as inhibitors. These complexes are insoluble in cold water, and to destroy them a higher temperature is required (Morrison, 1988). They are also responsible for the 'stress-overshoot' phenomenon - a rapid increase in shear stress at a selected shear rate (Divoux et al., 2011) was visible in the flow curves (Fig. 3c). The 'hump' typical of this starch denotes the creation of a weak structure, involving the above-mentioned amylose-lipid complexes (Zhou et al., 1998). The gelatinization/freeze-drying process caused a lowering of the 'hump' resulting from the destruction of amylose-lipid complexes. Such a collapse could be the effect of the starch retrogradation process. On the other hand, after modification a decreasing tendency of apparent viscosity throughout the whole range of shear rate was observed due to the diminishing weight of a large molecules $\left(\mathrm{M}_{\mathrm{w}}>1000000 \mathrm{~g} \mathrm{~mol}^{-1}\right)$, which should be attributed to a better dissolution of the polysaccharide aggregates (Fig. 2).

The applied modification of starch gels led to changes in their rheological properties (Fig. 3, Table 3). The lowering of the viscosity of modified mixtures created gels more susceptible and fragile to shear. Removing water from the frozen starch gels by means of the freeze-drying process results in the destruction of the hydrogen bonds stabilizing the structure. Viscosity reduction was one of the effects of this process, which was also reflected in the lower values of consistency coefficient $(K)$ in comparison with native starch gels. However, as shown statistical analysis in the case of WSL and RSL these changes were statistically insignificant. The OSN gel was described by the higher values of parameter $K$. However, fitting of the rheological model was worse than the other gels as indicated by $\mathrm{R}^{2}$ values. Gels of other freeze-dried starches (WSL and RSL) were characterized by more than 20-times lower values of the consistency coefficient in comparison with OSL.

Summarized areas of the hysteresis loop values (Table 4) have proved that both native and modified starch gels showed only thixotropic properties. However, the modification process decreased the value of thixotropy in all samples. Nevertheless in the case of RSL and WSL this decrease was statistically insignificant. Thixotropic behaviour of native cereal starch gels confirmed inhomogenity of these mixtures: they contained not only pasted granules but also swollen and partially pasted granules. As it was confirmed by Krystyjan et al. (2016) and Sikora et al. (2015), the pasting temperature of starch significantly influenced the rheological parameters of the resulted gels which may have thixotropic, antithixotropic or mixed thixotropic/

T a b l e 4. Parameters of Ostwal de-Waele model and area of hysteresis loop

\begin{tabular}{|c|c|c|c|c|c|}
\hline \multirow{2}{*}{ Sample } & \multicolumn{3}{|c|}{ Ostwald-de Waele model } & \multicolumn{2}{|c|}{ Area of hysteresis loop $\left(\mathrm{Pa} \mathrm{s}^{-1}\right)$} \\
\hline & $K\left(\mathrm{~Pa} \mathrm{~s}^{\mathrm{n}}\right)$ & $n$ & $\mathrm{R}^{2}$ & Thixotropy & Antythixotropy \\
\hline WSN & $2.54 \pm 0.48 \mathrm{a}$ & $0.43 \pm 0.02 \mathrm{c}$ & $0.9996 \pm 0.0001$ & $136.5 \pm 15.1 \mathrm{a}$ & 0 \\
\hline WSL & $0.59 \pm 0.11 \mathrm{a}$ & $0.46 \pm 0.02 \mathrm{c}$ & $0.9994 \pm 0.0001$ & $121.0 \pm 13.5 \mathrm{a}$ & 0 \\
\hline RSN & $1.36 \pm 0.06 \mathrm{a}$ & $0.55 \pm 0.00 \mathrm{~d}$ & $0.9997 \pm 0.0001$ & $120.3 \pm 10.0 \mathrm{a}$ & 0 \\
\hline RSL & $1.06 \pm 0.12 \mathrm{a}$ & $0.57 \pm 0.04 d$ & $0.9998 \pm 0.0001$ & $114.5 \pm 8.5 \mathrm{a}$ & 0 \\
\hline OSN & $45.07 \pm 8.80 \mathrm{c}$ & $0.10 \pm 0.01 \mathrm{a}$ & $0.8922 \pm 0.0055$ & $2911.9 \pm 119.9 \mathrm{c}$ & 0 \\
\hline OSL & $29.05 \pm 7.87 b$ & $0.17 \pm 0.04 \mathrm{~b}$ & $0.8898 \pm 0.1389$ & $2430.5 \pm 155.3 b$ & 0 \\
\hline
\end{tabular}

Explanations as in Table 1. 
antithixotropic characteristics. The authors confirmed that at $95^{\circ} \mathrm{C}$ incomplete starch pasting took place. In turn low viscosity of modified starch gels was caused by a retrogradation of amylose which took place during cooling of the gels before their freeze-drying. According to Juszczak et al. (2004) the retrograded amylose does not affect the formation of the continuous phase, and the structure of these gels is very susceptible to shear. However, as it was shown by statistical analysis (Table 4), it is only in the modified oat starch gels that the retrogradation of amylose had an effectual impact on the rheological properties. The other two modified starch gels were more stable.

\section{CONCLUSIONS}

1. The gelatinization/freeze-drying process destroyed the granular structure of native starches.

2. New products had a strongly developed surface, uniform structure and high porosity.

3. Modification resulted in a decrease of apparent amylose content determined by the colorimetric method, but these changes were not confirmed by a molar mass evaluation. In fact, the amylose content after modification remained unchanged, the same as the fat content, and the observed change in iodine affinity of amylose was most probably due to the formation of amylose-lipid complexes.

4. The modification of starches had a pronounced effect on the WBC and solubility. In all cases these parameters were greater in comparison with native starches.

5. Molecular weight of starches slightly decreased after modification, which resulted in a lower viscosity. However, it was only in case of oat starch that the observed changes were significant.

6. Such kinds of modified starches could be used as biodegradable packaging materials, absorbents or hydrophilic matrices. In the food industry they may be used as a pad for absorbing any liquid seeping out from the product, such as meats or they may be added as ingredients directly to the product that retain their moisture and prolong the freshness of the foodstuff, such as in bread. Further studies are necessary to check the applicability of these preparations in such areas.

Conflict of interest: Authors have not declared a conflict of interest.

\section{REFERENCES}

Autio K. and Eliasson A.C., 2009. Oat starch. In: Starch: Chemistry and Technology, 3rd Edition (Eds J. BeMiller, R. Whistler). Academic Press, New York, USA.

Buksa K., Nowotna A., Ziobro R., and Gambuś H., 2013. Rye flour enriched with arabinoxylans in rye bread making. Food Sci. Technology Int., 21(1), 45-54.
Craig S.A.S., Maningat C.C., Seib P.A., and Hoseney R.C., 1989. Starch paste clarity. Cereal Chem., 66(3), 173-182.

Divoux T., Barentin C., and Manneville S., 2011. Stress overshoot in a simple yield stress fluid: An extensive study combining rheology and velocimetry. Soft Matter, 7, 9335.

Gidley M.J., Hanashiro I., Hani N.M., Hill S.E., Huber A., Jane J.L., Liu Q., Morris G.A., Rolland-Sabaté A., Striegel A.M., and Gilbert R.G., 2010. Reliable measurements of the size distributions of starch molecules in solution: Current dilemmas and recommendations. Carbohydrate Polymers, 79(2), 255-261.

Gilbert R.G., Gidley M.J., Hill S., Kilz P., Rolland-Sabaté A., Stevenson D.G., and Cave R.A., 2010. Characterizing the size and molecular weight distribution of starch: why it is important and why it is hard. Cereal Foods World, 55(3): 139-143.

Gomand S.V., Verwimp T., Goesaert H., and Delcour J.A., 2011. Structural and physicochemical characterisation of rye starch. Carbohydrate Res., 346(17), 2727-2735.

Gudmundsson M. and Eliasson A.-C., 1989. Some physicochemical properties of oat starches extracted from varieties with different oil content. Acta Agriculturae Scandinavica, 39(1), 101-111.

Gumul D., Krystyjan M., Buksa K., Ziobro R., and Zieba T., 2014. The influence of oxidation, extrusion and oxidation/ extrusion on physico-chemical properties of potato starch. Starch/Staerke, 66(1-2), 190-198.

Hofmann T., Linke L., Tsiapouris A., and Ziems A., 1998. Porous Materials Made from Starch. Chemical Eng. Technol., 21, 580-584.

Jouppila K. and Roos Y.H., 1997. The physical state of amorphous corn starch and its impact on crystallization. Carbohydrate Polymers, 32(2), 95-104.

Juszczak L., Fortuna T., Witczak M., and Dymel A., 2004. Rheological properties of freeze-dried wheat starch/galactomannan gels. J. Food Nutrition Sci., 13(2), 157-162.

Krystyjan M., Sikora M., Adamczyk G., Dobosz A., Tomasik P., Berski W., Lukasiewicz M., and Izak P., 2016. Thixotropic properties of waxy potato starch depending on the degree of the granules pasting. Carbohydrate Polymers, $141,126-134$.

Leach H.W., 1965. Gelatinization of starch. In: Starch Chemistry and Technology, Vol. 1 (Eds E.L. Whistler and E.F. Paschall). Academic Press, New York, London.

Lee S.W. and Rhee C., 2007. Effect of heating condition and starch concentration on the structure and properties of freeze-dried rice starch paste. Food Res. Int., 40(2), 215-223.

Leszczyński W., 1992. Changes in starch properties caused by physical factors (in Polish). In: Materials of the Summer Starch School "Problems of starch modification", June 1-5, Zawoja, Poland.

Morrison W.R., 1988. Lipids in cereal starches: A review. J. Cereal Sci., 8(1), 1-15.

Morrison W.R. and Laignelet B., 1983. An improved colorimetric procedure for determining apparent and total amylose in cereal and other starches. J. Cereal Sci., 1(1), 9-20. 
Nussinovitch A., Gershon Z., and Peleg L., 1998. Characteristics of enzymatically produced agar-starch sponges. Food Hydrocolloids, 12, 105-110.

Paton D., 1977. Oat starch. part 1, extraction, purification and pasting properties. Die Starke, 29, 149-180.

Pietrzyk S. and Fortuna T., 2005. Impact of starch type and its oxidation conditions on retrogradation properties (in Polish). Żywność: Nauka, Technologia, Jakość, 2(43), 23-32.

Praznik W., Buksa K., Ziobro R., Gambuś H., and Nowotna A., 2012. The effect of long-term alkali treatment on the molecular characteristics of native and extruded starches at $35^{\circ} \mathrm{C}$. Starch/Staerke, 64(11), 890-897.

Ratti C., 2012. Freeze-drying process design. In: Handbook of Food Process Design (Eds J. Ahmed and M.S. Rahman). Blackwell Publishing Ltd., Oxford, UK.

Richter M., Augustat S., and Schierbaum F., 1969. Ausgewählte Methoden der Stärkechemie. VEB Fachbuchverlag, Leipzig, Germany.

Sánchez L., Torrado S., and Lastres J., 1995. Gelatinized/ freeze-dried starch as excipient in sustained release tablets. Int. J. Pharmaceutics, 115(2), 201-208.

Shi A.M., Li D., Wang L.J., and Adhikari B., 2012a. Rheological properties of suspensions containing cross-linked starch nanoparticles prepared by spray and vacuum freeze drying methods. Carbohydrate Polymers, 90(4), 1732-1738.

Shi A.M., Wang L.J., Li D., and Adhikari B., 2012b. The effect of annealing and cryoprotectants on the properties of vacuum-freeze dried starch nanoparticles. Carbohydrate Polymers, 88(4), 1334-1341.

Sikora M., Adamczyk G., Krystyjan M., Dobosz A., Tomasik P., Berski W., Lukasiewicz M., and Izak P., 2015. Thixotropic properties of normal potato starch depending on the degree of the granules pasting. Carbohydrate Polymers, 121, 254-264.

Sikora M., Krystyjan M., Tomasik P., and Krawontka J., 2010. Mixed pastes of starches with guar gum. Polimery/ Polymers, 55(7-8), 582-590.

Spieles G., Marx T., Heschel I., and Rau G., 1995. Analysis of desorption and diffusion during secondary drying in vacuum freeze-drying of hydroxyethyl starch. Chemical Eng. Processing: Process Intensification, 34(4), 351-357.

Swinkels J.J.M., 1985. Composition and properties of commercial native starches. Starch - Stärke, 37(1), 1-5.

Tomasik P. and Schilling C.H., 2004. Chemical modification of starch. In: Advances in Carbohydrate Chemistry and Biochemistry, Vol. 59 (Ed. D. Horton). Academic Press, Elsevier Inc.

Tomasik P. and Zaranyika M.F., 1995. Nonconventional methods of modification of starch. Advances in Carbohydrate Chemistry and Biochemistry, 51, 243-320.

Zhou M., Robards K., Glennie-Holmes M., and Helliwell S., 1998. Structure and pasting properties of oat starch Review. Cereal Chemistry, 75(3), 273-281. 